\title{
Arkeolojik Verilere Göre Doğu Trakya Kuzey Yolu*
}

\author{
Ergün Karaca**
}

\section{$\ddot{\mathbf{O} z}$}

Küçük Asya ile Avrupa arasında geçiş noktası konumundaki Doğu Trakya, her iki kıtadan gelen yolların geçiş ve birleşme yeri olmuştur. Kuzey Yolu, bölgeden geçen Via Egnatia ve Via Militaris ile birlikte üç ana yoldan biridir. Pontos Euksenos (Karadeniz)'in batısı veya kuzeyine ya da tam tersi buradan Küçük Asya'ya doğru yapılan seferlerde MÖ 6. yüzyıldan MS 19. yüzyıla kadar tüm kara orduların kullandığı güzergâh olmuştur. Buna karşın Kuzey Yolu’nun güzergâhı üzerindeki arkeolojik veriler diğer yollar kadar değerlendirilmemiştir. Bu makalede arazi çalışması sırasında tespit edilen ve incelenen başta Kurtdere Köprüsü olmak üzere köprü, yol kalıntısı ve mil taşı kullanılarak Kuzey Yolu'nun Doğu Trakya Bölgesi içindeki güzergâhı tespit edilmeye çalışılmıştır. Ayrıca Kuzey Yolu'nun güneyindeki Via Militaris ile kuzeyindeki Salmydessos kenti ile bağlantı sağlayan yollar arkeolojik verilere göre değerlendirilmiştir.

Anahtar Kelimeler: Antik Çağ'da Ulaşım, Mil taşı, Tabula Peutingeriana, Köprü.

* Bu çalışma Trakya Üniversitesi, Bilimsel Araştırma Projeleri Birimi (TÜBAP) tarafından TÜBAP -2018/119 numaralı proje kapsamında desteklenmiştir. Makalede kullanılan harita ve fotoğraflar aksi belirtilmediği sürece tarafıma aittir. Ayrıca metinde kullanılan bilgiler, tarafimca 2014 yılında Kültür ve Turizm Bakanlı̆̆ı’nın izni ve Kırklareli Müzesi’nin denetiminde gerçekleştirilen yüzey araştırmasının verileridir.

** Dr., Trakya Üniversitesi, Edebiyat Fakültesi, Arkeoloji Bölümü, Edirne/TÜRKIYYE, ergunkaraca@trakya.edu.tr ORCID: 0000-0002-0270-3258

Makale Gönderim Tarihi: 02.05.2018 - Makale Kabul Tarihi: 09.01.2020 


\title{
The North Road of Eastern Thrace according to Archeological Data
}

\begin{abstract}
East Thrace, which is the transition point between Asia Minor and Europe, has become the transit and the junction point of roads from both continents. The North Road is one of three main roads with Via Egnatia and Via Militaris that pass through the region. This region is the route that all armies used between the 6th century B.C. and the 19th century A.D. in expeditions from Asia Minor to the west or north of the Pontus Euksinus (the Black Sea) or vice versa. However, the archaeological data found on the route to North Road were not studied as much as those of the other roads. In this article, efforts were made to locate the route of the North Road in the Eastern Thrace Region by using, primarily the Kurtdere Bridge, and remains of bridges, roads, and milestones found and studied during fieldwork. Also, the roads connecting Via Militaris to the south of the North Road and the Salmydessos to the north of the North Road were evaluated according to the archaeological data.
\end{abstract}

Keywords: Transportation in the Antique Age, Milestone, Tabula Peutingeriana, Bridge.

\section{Giriş}

Antik Çă̆ yolları ticaret, haberleşme ve seferlerde iklimden etkilenmeden hızlı ilerleme açılarından önemlidir. Roma İmparatorluğu’na kadar doğal vadi geçitleri ve ahşap köprülerden oluşan yollar için yüzey şekillerine çok müdahale edilmemiştir. Sınırları genişleyen Roma İmparatorluğu, orduyu hızlı sevk edebilmek ve barış zamanında başkent ile eyaletler arasındaki iletişim için yol mühendisliğini önemsemiştir. Bu nedenle ordu birliklerinde köprü ve yol yapımında uzman askeri mühendisler istihdam edilmiştir. Yumuşak zeminlerde taş döşemeler ile inşaat teknolojisinin gelişmesiyle taş köprüler yapılmış ve mesafeyi gösteren mil taşları (miliaria) dikilmiştir.

\section{Doğu Trakya'daki Ana Yollar}

Küçük Asya ile Avrupa arasında geçiş noktası konumundaki Doğu Trakya, batı, kuzeybatı ve kuzeyden gelen yolların geçiş ve birleşme yeri olmuştur. Doğu Trakya'da üç ana yol ile bunlar arasında bağlantı sağlayan ara yollar bulunmakta- 
dır. Doğu Trakya'dan geçen ana yolar; Via Egnatia, Via Militaris / Via Traiana (Ordu Yolu), Sahil Yolu ve Kuzey Yolu'dur.

Bu yolların en ünlüsü, Adriatik Denizi (Mare Adriaticum)'nin doğu kıyısındaki Dyrrhakhion (Durres) ve Apollonia kentlerinden başlayarak doğudaki Byzantion/Konstantinopolis (İstanbul) kentinde sona eren ve bölgenin güneyi boyunca uzanan batı-doğu doğrultulu Via Egnatia'dır . Singidunum (Belgrad)'dan başlayıp, Hadrianopolis (Edirne) üzerinden, kuzeybatı-güneydoğu doğrultulu bölgenin ortasından geçerek Perinthos'ta Via Egnatia ile birleşen Via Militaris veya Via Traiana (Ordu Yolu)'dır². Kuzey Yolu ise, Kimmeria (Kırım)'dan başlayıp Trakya'nın Pontos Euksenos (Karadeniz) kıyısını takip ederek Apollonia Pontike (Sozopol) üzerinden Byzantion/Konstantinopolis'e ulaşan Sahil Yolu'dur³. Bölgenin bir diğer önemli ve bu çalışmanın konusunu oluşturan yolu ise, "Kuzey Yolu"dur4 (Harita 1 ve 2).

1 Via Egnatia ile ilgili daha detaylı bilgi için bkz. Işsk Şahin, "Roma Yolu "Via Egnatia", Sibel Turan (ed.), Keşan Sempozyumu Bildiri Tam Metinleri, 15-16 Mayss 2003, İstanbul 2006, ss. 70-74, Mustafa Hamdi Sayar, "Via Egnatia on Eastern Thrace", Via Egnatia Revisited. Common Past, Common Future with the Lectures of the Conference of February 2009, Driebergen 2010, ss. 43-44, Anna Avramea, "MÖ. 2. Yüzyıl İle MS. 6. Yüzyıl Arasında Via Egnatia'nın Güzergâhı ve İşlevi”, Sol Kol, Osmanl Egemenliğinde Via Egnatia (1380-1699), Tarih Vakfi Yurt Yayınları, İstanbul 1999, ss. 3-7, Andreas Kuelzer, "The Byzantine Road System in Eastern Thrace", Byzantinische Forschungen, Cilt: 30, 2011, s. 181, David H. French, Roman Roads and Milestones of Asia Minor, Vol.: 3 Fasc. 3. 1, British Institute at Ankara (Electronic Monograph 1), Ankara 2012, Ergün Karaca, Milattan Önce Birinci Binde Doğu Trakya, Homer Yayınları, İstanbul 2019, ss. 36-37. Via Egnatia Osmanlı İmparatorluğu Dönemi’ nde "Sol Kol" adıyla kullanılmaya devam edilmiştir. Bkz. Halime Doğru, XIII.-XIX. Yüzyllar Arasnda Rumeli’de Sağ Kolunun Siyasi, Sosyal, Ekonomik Görüntiusü ve Kozluca Kazasl, Anadolu Üniversitesi Yayınları, Eskişehir 2000, s. 32.

2 Konstantin Yosif İreçek, Belgrad İstanbul Roma Askeri Yolu, Çev. Ali Kemal Balkanlı, Kültür Bakanlığı Yayınları, Ankara 1990, Karaca, a.g.e., ss. 37-38. Osmanlı imparatorluğu Dönemi”nde "Orta Kol" veya "İstanbul Yolu" olarak adlandırılmıştır. Bkz. Kuelzer, a.g.e., s. 181; Doğru, a.g.e., s. 32.

3 Tabula Peutingeriana'da Sahil Yolu üzerinde Philias ve Scyllam ara istasyonların olduğu gösterilmiştir. Bu yol haritada da olmasına karşın varlı̆̆ı konusunda şüpheler vardır. Yol güzergâhının coğrafyasına bakıldığında, Astikus Dağı'nın kıyıya dik olduğu, kıyıdan uzaklaştığı alanlarda ise longoz ormanları ve genelinde yoğun ormanlarla kaplı olduğu görülür. Bu durumda antik çağ teknolojisi ile bu yolu işlevsel hale getirmek ve bunu sürekli açık halde tutmak zor ve masraflıdır. Ayrıca bu yolu yapmak için büyük teknolojik makinelere ihtiyaç duyulduğunda Antik Çağ teknolojisi bunu yapmak pek mümkün gözükmemektedir. Bununla birlikte, Tunç Çağı’ndan beri kullanıldığı bilinen, kıyıyı takip eden deniz yolunun bu güzergâhtan daha ekonomik ve kısa olması da bu yola ihtiyacı azaltmaktadır.

4 Mitko Madzharov, Roman Roads in Bulgaria. Contribution to the Development of Roman Road System in the Provinces of Moesia and Thrace, Faber Yayınevi, Veliko Tarnovo 2009, s. 184, Karaca, a.g.e., ss. 38-39. Osmanlı imparatorluğu Dönemi'nde "Sağ Kol” veya "Kinm-Karadeniz Ticaret Tolu” olarak adlandırılmıştır. Ayrıntılı bilgi için bakınız Sema Altuhan, "XVIII. yy'da Silistre Eyaletinde Ha- 


\section{Kuzey Yolu}

Doğu Trakya'nın önemli yollarından biri durumundaki Kuzey Yolu'nun tam güzergâhı hakkında, Tabula Peutingeriana haritası haricinde bilgi bulunmamaktadır $\left(\right.$ Harita $\mathbf{2}^{5}$ ). Genel olarak tanımlanacak olursa Byzantion/Konstantinopolis'den başlayan bu yol, önce kuzeybatı daha sonra ise kuzeye dönerek Astikus (Istranca/ Yıldız) Dağı'nı aşar, Pontos Euksenos kıyısını takip ederek İstros (Tuna) Nehri ve onun ilerisine Kırım (Kimmeria)'a kadar devam eder.

Kuzey Yolu’nun Roma İmparatorluk Dönemi öncesi güzergâhı hakkında ne yazık ki çok fazla arkeolojik veriye sahip değiliz. Buna karşın antik yazarların, bölgeden geçen orduların izledikleri güzergâhlar hakkında fazla detaya girmeden verdikleri bilgiler ile Roma İmparatorluk, Doğu Roma İmparatorluğu ve Osmanlı İmparatorluğu dönemlerine ait yol kalıntıları, köprüler ve mil taşları sayesinde önceki dönemlerin güzergâhı hakkında bilgi sahibi olunmaktadır.

Bu güzergâh hakkında ilk bilgiyi Herodotos'dan almaktayı. Herodotos, Pers Kralı I. Dareios'un MÖ 513 yılındaki İskit Seferi’ni anlatırken kralın geçtiği güzergâh hakkında genel bilgi vermiştir ${ }^{6}$. Bosphoros Thrakios (İstanbul Boğazi)'dan Doğu Trakya'ya geçen I. Dareios, Astikus Dağları'nın güney etekleri boyunca bölgenin içinde ilerlemiş; daha sonra Astikus'un yükseltisinin azalmaya başladığı batıdan, Tanzos (Tunca) Vadisi'ni izleyerek kuzeye doğru, İstros Nehri’ne doğru seferine devam etmiştir. Herodotos, I. Dareios'un Trakya topraklarına girdikten sonra Tearos Nehri'nin ${ }^{7}$ kaynaklarında üç gün dinlendiğini, şifalı sıcak ve soğuk su kaynaklarının bulunduğu bu yeri beğenen kralın buraya bir sütun diktirdiğini de belirtir ${ }^{8}$. Herodotos, aynı seferden bahsederken Pontos Euksenos kıyısındaki Apollonia Pontike ile Propontis (Marmara) Denizi kıyısında ve Perinthos (Mar-

berleşme Ağ̣: Rumeli Sağ Kol Menzilleri”, Osmanh Tarihi Araştırma ve Uygulama Merkezi Dergisi, Cilt 18, Sayı 18, 2005, ss. 1-20.

5 Tabula Peutingeriana için https://www.tabula-peutingeriana.de/index.html adresinden faydalanılmıştır.

6 Karaca, a.g.e., s. 38.

7 Mustafa Hamdi Sayar, Herodotos'un ve MS 19. yüzyılda bölgeye gelen seyyahların değerlendirmesiyle Poyralı Deresi'nin Kontadestos, Kaynarca Deresi'nin ise Tearos olması gerektiğini belirtmiştir. Mustafa Hamdi Sayar, "Kırklareli’nde Persler: Dareios'un Kırklareli Üzerindeki Seferi”, Yildı Dağlan ve Yakn Çevresi Tarih Araştırmalan, Arkeoloji ve Sanat Yayınları, İstanbul 2006, ss. 42-43.

8 Herodotos, Herodot Tarihi, IV, ss. 89-91. 
mara Ereğlisi) yakınlarındaki Heraion (Karaevlialtı) kentinin tam ortasında, her iki kente de iki günlük mesafede olduğu bilgisini verir9 9 .

Kesin bilgilere ulaşlamasa da bu güzergâhı kullanan bir diğer kişinin Makedonia Kralı II. Philippos olduğu düşünülmektedir. II. Philippos, Perinthos ve Byzantion’u uzun süredir kuşatırken MÖ 339 yılında krallığının kuzeydoğusunda, İstros Nehri’nin Pontos Euksenos'a döküldüğü yerde bulunan İskitler'in sorun çıkarmaları üzerine bu iki kent üzerindeki kuşatmayı kaldırmış ve buradan doğrudan kuzeye, İskitler üzerine sefere çıkmıştır ${ }^{10}$. Kaynaklar, II. Philippos'un sefer güzergâhı hakkında bilgi vermemelerine karşın, Perinthos ve Byzantion'dan kuzeye doğru hareket eden kral, olasılıkla Pers Kralı I. Dareios'un gittiği yolu izlemiştir ${ }^{11}$. Daha sonra ise Hellenistik Dönem'in önemli krallarından ve Doğu Trakya'da hüküm süren Lysimakhos, MÖ 313/2 yllında kendisine isyan eden Pontos Euksenos'un batı kıyısındaki Kallatis (Mankalya), İstros (İstria) ve Odessos (Varna) gibi kentler üzerine yaptığı seferlerde de Astikus Dağı'nı aşmak için bu güzergâhı kullanmış olmalıdır'12.

Büyük askeri seferler vasıtasılla genel olarak bildiğimiz bu güzergâh, ancak Roma Imparatorluk Dönemi'nde tam anlamıla bir yol halini almıştır. Roma İmparatorluk Dönemi’nde güzergâhı netleşmeye başlayan Kuzey Yolu, Tabula Peutingeriana'ya işlenmiştir. Böylece Kuzey Yolu üzerinde konaklama yerleri ve olasılıkla mesafe gösteren miltaşlarının yerleştirildiği bir yol haline gelmiştir.

Tabula Peutingeriana'da görüldüğü üzere, İstros Nehri’nin Pontos Euksenos'a döküldüğü yerin güneyindeki Salsovia'dan başlayan yol, kıyııı izleyerek Ad Stoma, Histriopolis, Tomis (Köstence), Callatis, Trissa, Bizone, Dyosinopoli, Odessos, Erite, Templo Iovis, Mesembria (Nesebar), Ancialis (Pomorie)'ye gelir. Ancialis'den sonra kıyıdan ayrılan yol iç kısımdaki Pvdizo'ya ulaşır. Haritaya göre, Pvdizo'dan sonra olasılıkla Ergienes (Ergene) Nehri’ni geçen yol, güneydoğuya doğru Vt Svrgas/Utsurgae, Perinthos'dan gelen ara yol ile birleşme noktası olan Cenopvrio/Caenophrurium'a gelir. Buradan Küçükçekmece Gölü’nün kuzeyindeki bu yol güzergâhının son istasyonu Melantiana'dan geçerek Rhegion

9 Herodotos, Herodot Tarihi, IV, s. 90.

10 Marcus Iulianus Iustinus, Epitome of the Philippic History of Pompeius Trogus, IX. 2; James R. Ashley, The Macedonian Empire, The Era of Warfare under Philip II and Alexander the Great, 359-323 B.C., McFarland Yayınevi, Londra 1998, ss. 148-149; Zosia H. Archibald, The Odrysian Kingdom of Thrace, Orpheus Unmasked, Oxford Üniversitesi Yayınları, Oxford 2008, s. 237, Karaca, a.g.e., s. 38.

11 Madzharov, a.g.e., s. 185; Martin Gyuzelev, The West Pontic Coast between Emine Cape and Byzantion during the First Millennium BC, Lotus Yayınevi, Burgaz 2008, s. 72.

12 Madzharov, a.g.e., ss. 72-73, Karaca, a.g.e., s. 38. 
(Küçükçekmece) yerleşimi civarında Via Egnatia ile birleşerek doğuya doğru devam eder ve Konstantinopolis'de sona erer (Harita 2).

Yol mühendisliği ve teknolojisi Roma İmparatorluğu Dönemi’nden sonra Doğu Roma ve Osmanlı İmparatorlukları dönemlerinde de çok fazla değişmediğinden, güzergâhlar hemen hemen aynı kalmıştır ${ }^{13}$. Roma İmparatorluğu Dönemi’ndeki Kuzey Yolu'nun güzergâhı, daha sonraki dönemlerde de hiç değişmeden kullanılmış olmalıdır.

Kimmeria (Kırım)'dan başlayıp Pontos Euksenos'un batı kıyısını takip ederek Tomis (Köstence), Odessos (Varna), Ancialis, Apollonia Pontike ve Burgaz Körfezi’nin güneybatısında bulunan Pudizo'da diğer yollar ile birleşir. Buradan güneye doğru ve Ut Surgas (olasllkla Malko Tarnova) yerleşimlerini geçtikten sonra Rezerve Deresi' in $^{14}$ ve Astikus Dağı'nı aşarak Doğu Trakya Bölgesi’ne girer. Buradan Herakleia (Kırk-Kilise/ Kırklareli) civarından ${ }^{15}$ güneydoğuya doğru Gehenna (Kaynarca), Brysis (Pınarhisar), Bizye (Vize), Utsurgae, Strantza (Binkılıç), Makra Teiche (Gümüsspınar), Ad Statuas (olasılıkla İnceğiz ${ }^{16}$, Cenopurio (Küçüksinekli), Melantiada (Yarımburgaz ${ }^{17}$ )'dan sonra

13 Doğu Trakya'nın yollarına bakıldığında günümüzde de İstanbul'dan başlayan devlet yolu Çatalca, Saray, Vize, Pınarhisar üzerinden Kırklareli’ye ulaşır. Yol buradan ikiye ayrılarak, batıya doğru Edirne'ye, kuzeye doğru ise, Demirköy üzerinden Bulgaristan'a doğru devam eder.

14 Rezerve Deresi'nin üzerinde, İncesırt Köyü sınırları üzerinde Osmanlı Dönemi’ne tarihlenen taş köprü kalıntısı bulunmaktadır. Bkz. dipnot 37 .

15 Kırklareli, Osmanlı İmparatorluğu Dönemi’nde (18. yüzyll) menzil olarak kullanılmıştır. Bkz. Altuhan, a.g.e., ss. 1-20.

16 İreçek, İnceğiz’in Ad Statuas olabileceğini belirtmektedir. Bkz. İreçek, a.g.e., 49. İnceğiz’in yaklaşı 2,5 km kadar batısındaki Maltepe'de yapılan kurtarma kazısında Roma ve Doğu Roma İmparatorlukları dönemlerine tarihlenen bir yerleşim ve nekropol alanı bulunmuştur. Maltepe yerleşimi için bkz. Alpay Pasinli-Turan Gökylldırım vd., "İnceğiz-Maltepe Nekropolü 1992 Yllı Kurtarma Kazısı", IV. Müze Kurtarma Kazllan Semineri, 1994, ss. 339-356; Alpay Pasinli-Turan Gökyıldırım vd., "Inceğiz-Maltepe Nekropolü 1993 Yılı Kurtarma Kazısı", V. Müze Kurtarma Kazllar Semineri, 1995, ss. 345-364; Alpay Pasinli-Turan Gökylldırım vd., "Çatalca-İnceğiz Köyü Maltepe Nekropolü 1994 Yılı Kurtarma Kazısı", VI. Müze Kurtarma Kazzlan Semineri, 1996, ss. 205-219; Alpay Pasinli-Turan Gökyıldırım vd., "Çatalca-İnceğiz Köyü Maltepe Nekropolü 1995 Yılı Kurtarma Kazısı", VII. Müze Kurtarma Kazılan Semineri, 1997, ss. 77-88.

17 Yarımburgaz civarında, Küçükçekmece Gölü’nün kuzeyinde bulunan Nakkaş/Menekşe Deresi üzerindeki Roma Köprüsü ile aynı gölün hemen kuzeyinde yer alan Osmanlı Imparatorluğu Dönemi'ne ait Odabaşı Köprüsü bu güzergâhı göstermesi açısından önemlidir. Her iki köprü hakkında bilgi için bakınız Binnur Kıraç-Burcu B. Cantimur-Mevlüde Kaptı, "Tarihi Kâgir Köprülerde Koruma Yaklaşımlarının İrdelenmesi: Menekşe/Nakkaş (Roma) Köprüsü, Odabaşı Köprüsü ve Ferhatpaşa Köprüsü”, 5. Tarihi Eserlerin Güçlendirilmesi ve Geleceğe Güvenle Devredilmesi Sempozyumu, Erzurum 2015, ss. 435-443. Bu güzergâh Küçükçekmece Gölü’nün doğu ve kuzeyinden, Çatalca, Vize, Pınarhisar ve Kırklareli üzerinden Edirne'yi geçip buradan sonra kuzeye veya batıya yönelerek asıl hedeflerine doğru seferlerine devam etmişlerdir. Ayrıntılı bilgi için bkz. 
Via Egnatia ile birleşir ve sonra doğuya doğru devam ederek Byzantion/Konstantinopolis'e ulaşır ${ }^{18}$.

Astikus Dağları üzerinden geçen bu yol ile ilgili ikinci bir güzergâh ise, dağın batısından, Tanzos Vadisi boyunca devam eden yoldur. Bu güzergâh, Ancialis'den batıya doğru Aqvis Calidis (Banevo) üzerinden devam eder, Cabilis (Kabile/Yanbol)'de ikiye ayrılır. Güneye doğru devam eden yol, Astikus Dağı'nın yükseltisinin azaldığı ve Tanzos Nehri’nin oluşturduğu doğal geçitten geçer. Astikus Dağı'nı aştıktan sonra bu yolda biri güneye Hadrianopolis'e doğru, diğeri ise doğuya doğru iki kola ayrılır. Doğuya doğru ayrılan yol, Skopelos/Polos (Yoğuntaş ${ }^{19}$ ) ve Petra $\left(\right.$ Kayali $\left.^{20}\right)$ üzerinden geçerek Herakleia civarında Ut Surgas'dan gelen yol ile birleşir ${ }^{21}$ (Harita 3).

\section{Kurtdere Köprüsü ve Yol Kalıntısı}

Yukarıda da belirtildiği üzere Kuzey Yolu için, Tabula Peutingeriana ile daha sonraki Doğu Roma İmparatorluğu ve Osmanlı İmparatorluğu dönemlerine ait yerleşim ve kaynaklara göre güzergâh verilmeye çalışılmıştır. Astikus Dağı'nın güney eteklerinde yer alan Brysis, Bizye, Skopelos/Polos gibi kale kalıntıları bu güzergâhın oluşturulmasında belirleyici olmuştur. Ancak yol güzergâhını net şekilde gösteren köprü ve yol kalıntısı gibi arkeolojik veriler çok fazla karşımıza çıkmamaktadır. Bu nedenle Kırklareli Merkez İlçe ile Pınarhisar ilçelerinin birleştiği, Üsküp Beldesi’nin sınırları içerisindeki Kurtdere Mevkii’nde bulunan köprü ayrı bir önem taşımaktadır (Harita 3).

Kurtdere Köprüsü, kuzey-güney istikametinde akan, ancak yazın kuruyan Kurt Deresi üzerinde inşa edilmiştir ${ }^{22}$ (Resim 1). Doğu-batı yönlü, tek kemerli köprünün inşa yeri kayalık olduğundan, kemer ayakları için temel açılmamış, ayakları oluşturan taş bloklar, doğrudan anakaya üzerine açılmış yuvalara oturtul-

Mehmet Yaşar Ertaş, "Savaşlarla Şekillenen Yollar: Osmanlı Devletinde Yol Sistemi”, Uluslararası Osmanl Öncesi ve Osmanh Tarihi Araştırmalan 6. Ara Dönem Bildirileri Kitabı, Meta Basım Matbaacilı, İzmir 2011, s. 632.

18 Kuelzer, a.ge., s. 184, Madzharov, a.g.e., ss. 198-200, Fig. 67 ve 68, Karaca, a.g.e., s. 39.

19 Yoğuntaş, Doğu Roma İmparatorluğu Dönemi’nde Skopelos, Osmanlı İmparatorluğu Dönemi’nde ise Polos adı kullanılmış, 1960'larda ise, bugünkü adı verilmiştir. Bkz. Nazif Karaçam, Efsaneden Gerçeğe Kirklareli, Kırklareli Belediyesi Yayını, Kırklareli 1995, ss. 503-504.

20 Kayalı, Doğu Roma İmparatorluğu Dönemi'nde Petra, Osmanlı Dönemi’nden 20. yüzyılın ortalarında kadar ise Bedre adı ile anılmıştır. Bkz. Karaçam, a.g.e., s. 506.

21 Kuelzer, a.g.e., s. 183, Madzharov, a.g.e., s. 200, Fig. 67 ve 68.

22 Köprü Koordinat: Doğu: 35536554, Kuzey: 4616342. 
muştur (Resim 2). Bu nedenle doğudaki ayak, batıdakinden daha aşağıya doğru inmektedir. Blok taşlarla kemer yan duvarları yapıldıktan sonra, bu kısmın içi moloz taş ve kireç harcı karışımından oluşan opus caementicium ile doldurulmuştur. Blok taşların birbirleriyle bağlantısında sadece kireç harcı kullanılmıştır. Köprünün güney tarafinda kemer bütünlüğü korunurken, kuzey tarafı define arayıcıları tarafindan tahrip edilmiştir ${ }^{23}$.

Köprünün doğu tarafinda, köprüden başlayarak yer yer tahrip olmasına karşın taş döşeli yaklaşık 3-3,5 m genişliğindeki yol Hacıfaklı-Kaynarca yol ayrımına kadar devam etmektedir (Resim 3). Bu yol ve köprünün batısındaki yol günümüzde köylüler tarafindan Kaynarca-Üsküp arasında kullanılmaya devam edilmektedir. Yol, iki yerleşim arasında yaklaşık olarak 10 km'lik bir güzergâh oluşturmaktadir.

Kurtdere Köprüsü, inşaat tekniği, kullanılan malzeme ve kemer tekniğine göre Roma İmparatorluk Dönemi’nde inşa edilmiştir. Hâlâ bütünlügünü koruyan köprü son ylllara kadar işlevini sürdürmüştür.

\section{Erenler Yol Kalıntısi}

Pınarhisar'a bağlı Erenler Köyü'nün ve Tavşantepe Kalesi şeklinde adlandırılan tepenin kuzeybatısında, kayalık alanda yaklaşık 120 cm'lik dingil genişliğine sahip, izlere göre en az dört farklı kuzeydoğu-güneybatı doğrultulu teker izlerine rastlanmışıı ${ }^{24}$ (Harita 3, Resim 4). Antik Çağ'da yol güzergâhında, çamurda araçların saplanmaması için imkânlar dâhilinde kayalık alanlar tercih edilmesinden dolayı Erenler yolu, tepenin güneyindeki toprak alan yerine zemini sert olması dolayısıyla kayalık kuzeyinden geçirilmiştir.

\section{Uçmakdere Köprüsü}

Kuzey Yolu güzergâhındaki bir diğer köprü ise, Uçmakdere Köprüsü’dür. Köprü, Vize kent merkezinin yaklaşık 2 km kadar kuzeybatısında Uçmakdere Mevkii'nde, modern Vize-Kırklareli karayolunun yaklaşık 60 m kadar kuzeydoğusunda yer alır ${ }^{25}$ (Harita 3).

Mevcut duruma göre Kurtdere Köprüsü, 4,90 cm genişliğe, 10 m kadar uzunluğa sahiptir. Köprünün kemer genişliği 3,60 cm ve dere tabanından yüksekliği 3,45 cm'dir. Köprü, kaçak kazı yapanlar tarafından ağır şekilde tahrip edilmektedir. Özellikle köprünün kuzey kısmı yıkılmış, batıdaki ayağın oturduğu ana kaya define olduğu gerekçesi ile derin şekilde kazılmıştır. Yol kalıntısı Koordinat: Doğu: 35547111 , Kuzey: 4609065. 
Köprü, kuzeydoğu-güneybatı doğrultulu akan Uçmakdere üzerinde, kuzeybatı-güneydoğu doğrultulu olarak inşa edilmiştir. Kesme taşlardan yapılan köprünün iç kısmı moloz taş ve harç karışımı ile doldurulmuştur. Kemer başlangıc1 (kemer yastığı) kısmından itibaren kemer kısmı yıkılan köprünün daha sonra üzerine demir profiller döşenerek düz şekilde 1960'lı yıllara kadar kullanımına devam edilmişsirir ${ }^{26}$ (Resim 5).

Köprü, taş işçiliği ve yapım tekniğine göre Geç Roma İmparatorluğu veya Osmanlı İmparatorluğu dönemlerine ait olmalıdır. Ancak Kuzey yolu ana arteri düşünüldüğünde, bu köprünün ilk kez Roma İmparatorluğu Dönemi’nde inşa edildiği ve daha sonrasında Geç Roma İmparatorluğu ile Osmanlı İmparatorluğu dönemlerinde onarıldığı veya tekrar yapılarak kullanımına devam edildiği tahmin edilmektedir ${ }^{27}$.

\section{Kuzey Yolu ile Via Militaris’i Birleştiren Ara Yollar}

Doğu Trakya’yı güneydoğu-kuzeybatı şeklinde kat eden Kuzey Yolu, bölgeden geçen diğer yollar, Via Militaris ve çevresindeki kentlerle de ara yollar vasıtasiyla bağlantılıdır.

Edirne'nin kuzeyinde iki adet mil taşı bulunmuş ve Edirne Arkeoloji Müzesi’nde korumaya alınmıştır. Hasanağa ile Sinanköy (Pravadi) arasında bulunan mil taşı MS 194-209 yıllarına, Süloğlu Barajı'nda bulunmuş mil taşı ise MS 337-350 ylllarına tarihlenmiştir ${ }^{28}$. Bu mil taşı, Hadrianopolis'den Tanzos Vadisi boyunca kuzeye giden yolu göstermesi açısından oldukça önemlidir29 (Harita 3).

Kırklareli merkezi ile Babaeski arasında, Şeytan Deresi Vadisi'ndeki Değirmencik Köyü’nün kuzeyinde, Dutlubahçe Mevkii’ndeki Hamam Deresi üzerinde

26 Mevcut haliyle köprünün ayaklar arasındaki açıllığı yaklaşık $260 \mathrm{~cm}$, genişliği yaklaşık $630 \mathrm{~cm}$ ve yüksekliği ise yaklaşık $3,40 \mathrm{~cm}$ 'dir.

27 Vize'de bulunmuş bir yazıtta, Bizans İmparatoru V. Konstantin (MS 741-775) tarafindan Vize ile Kırklareli arasında bulunan bir köprünün MS 773/74 tekrar yapılması için emir verdiği belirtilmektedir. Bu yazıtta belirtilen köprü, Uçmakdere Köprüsü olabilir. Yazıt hakkındaki bilgi için bkz. Kuelzer, a.g.e., s. 184.

28 Hasanağa ile Sinanköy (Pravadi) arasında bulunan mil taşında "Uğurlu olsun! Arabistan, Adiabene, Büyük Parth fatihi imparator Septimius Severus Partinax'a ve Augustuslar Aurelius Antoninus'a ve Publius (Gata)'a Hadrianopolishilerin şehri ... mil mesafede (diktirdi)" yazmaktadır. Süloğlu Barajı'nda bulunan mil taşında ise, "Efendilerimiz II. Konstantin, Kostas ve Constantius daima yenilmez Augustuslara ..." yazmaktadır. Her iki mil taşının bilgileri Edirne Arkeoloji Müzesi, eser sergi etiketlerinden alınmıştır. Bu mil taşları, Mustafa Hamdi Sayar tarafindan yayına hazırlanmaktadır.

29 Osmanlı İmparatorluğu Dönemi’nde de Edirne'den kuzeye, Yanbol'a doğru yapılan seferlerde Tunca Vadisi kullanılmıştır. Bkz. Doğru, a.g.ee, ss. 40, 44. 
tek kemerli Eski Lefeci Köprüsü bulunmaktadır ${ }^{30}$. Olasılıkla Roma İmparatorluk Dönemi’nde yapılan köprü, sonraki dönemlerde tadilat görerek günümüze kadar kullanıla gelmiştir (Resim 6). Bu köprü, Kuzey Yolu ve Via Militaris'i Kırklareli ile Babaeski (Burtudizon) hattında kuzey-güney yönlü olarak birleştiren yol üzerinde olmalıdir ${ }^{31}$ (Harita 3).

Kırklareli Arkeoloji Müzesi’nde, Vize’nin yaklaşık 7 km kadar güneyindeki Hasbuğa Köyü’nde bulunmuş mil taşı parçaları korunmaktadır. Bu mil taşının çok küçük bir parçası korunduğundan üzerindeki yazıttan anlamlı bir cümle çıkartılamamaktadır (Resim 7). Ancak harf karakterine göre olasılıkla Roma İmparatorluk Dönemi’ne tarihlendirilen ${ }^{32}$ parçalar, Kuzey Yolu üzerinde bulunan Bizye ile Via Militaris yolu üzerinde bulunan Druzipara (Büyükkarıştıran civarında) arasındaki bağlantı yolunu göstermesi açısından önemlidir (Harita 3).

\section{Kuzey Yolu ile Kuzeyindeki Yerleşimlerle Bağlantı Sağlayan Ara Yollar}

Vize'ye bağlı Akpınar Köyü'nün yaklaşı 3,5 km kadar kuzey doğusunda, Vize-Balaban yolunun kuzey kenarında "Yoltarla" olarak adlandırılan mevkiide anakaya üzerinde $120 \mathrm{~cm}$ ölçüsünde dingil genişliğinde kuzeydoğu-güneybatı doğrultulu iki yol izi ile kenarlarında defineciler tarafindan tahrip edilmiş kaya mezarları bulunmaktadır ${ }^{33}$ (Resim 8). Yine bu yolun doğusunda Vize-Balkaya yolunun 250-400 m kadar güneyinde Küpler Mevkii’nde doğu-batı doğrultulu, dingil açıllığ $120 \mathrm{~cm}$ ölçüsünde bir yol bulunmuştur ${ }^{34}$ (Resim 9). Bu yolun devamı tespit edilememiş olmakla birlikte, Vize-Balkaya-Aksicim üzerinden Kıyıöy’e ulaşan bugünkü köy yoluyla aynı güzergâhta olduğu açıktır. Bu tespit edilen yol kalıntıları, Kuzey Yolu'na bağlantılı Bizye ile Salmydessos (Medeia/Midye/Kıyıköy)

Köprü Koordinat: Doğu: 35517939, Kuzey: 4606545. Köprü, yaklaşık 3,80 cm genişliğinde, 4,50 $\mathrm{cm}$ uzunluğunda ve kenar genişliği $350 \mathrm{~cm}$ 'dir.

1 Eski Lefeci Köprüsü’nün yaklaşı 5 km kuzeyinde, Şeytan Deresi'nin doğu kıyısında Kanlıgeçit Mevkii'nde Kırklareli Müzesi tarafından yapılan çalışmada, MÖ 309-220 yılları arasına tarihlenen Lysimakheia (Bolayır) darbı sikkeler tespit edilmiştir. Sikkelerin etrafından yerleşim tespit edilememesi, olasılıkla bu güzergâhı kullanan kişiler tarafından bırakıldığı/düşürüldüğünü akla getirir. Sikkeler içini bakınız Melih Arslan, "Kırklareli Müzesi’ndeki Asilbeyli Lysimachia Definesi”, Belleten, Cilt: 72, Sayı: 263, Nisan 2008, ss. 5-52.

Yol kalıntısı Koordinat: Doğu: 35572144, Kuzey: 4606278.

Yol kalıntısı Koordinat: Doğu: 35574414, Kuzey: 4605917. 
arasındaki yol olmalıdır (Harita 3). Bu yol aynı zamanda iç bölge ile bir liman kenti Salmydessos'u iç bölgeye bağlayan güzergâhta bulunmaktadır.

Geç Antik Çağ’da daha çok kullanıldığı düşünülen İslambeyli Demirköy yolu karşımıza çıkmaktadır. İslambeyli Köyü'nün kuzeyindeki Çilingir Deresi'nin üzerindeki köprü, tek kemerli sadece kuzey ve güneyde bulunan ayak kısımları korunmuş taş ve kireç harcı kullanılarak yapılmıştır ${ }^{35}$. Köprü olasılıkla Doğu Roma İmparatorluğu veya Osmanlı İmparatorluğu dönemlerinde inşa edilmiş olmalıdır. Muhtemelen Poyralı civarından, Kuzey Yolundan ayrılan bu yol, İslambeyli Köyü'ndeki köprü geçilerek, Demirköy ${ }^{36}$ üzerinden Osmanlı Imparatorluğu Dönemi’ne tarihlenen Volçan Köprüsü ${ }^{37}$ de düşünülecek olursa, bu hat Doğu Roma İmparatorluğu ve Osmanlı İmparatorluğu dönemlerinde Astikus Dağı’nın kuzeyindeki Agathopolis (Ahtopol) ve Apollonia Pontike gibi yerleşimlere ulaşımı sağlayan kara yolu olmalıdır.

\section{Sonuç}

Bu makalede Kuzey Yolu üzerindeki Kurtderesi ve Uçmakdere Köprüleri, Erenler yol kalıntısi; bu yolun tali yollarındaki Eski Lefeci ve İslambeyli köprüleri, Hasbuğa ve Hasanağa mil taşları ile Akpınar Köyü’ndeki yol izleri arkeolojik veri olarak ilk kez değerlendirmiştir. Kuzey Yolu, deniz yolu alternatifi bulunması nedeniyle Doğu Trakya'dan geçen üç ana yolun diğer ikisi kadar bilinmez. Buna karşı, MÖ 6. yüzyıldan MS 19. yüzylla kadar tüm orduların kuzey (İstros veya Kimmeria'ya) veya ters yöndeki seferlerinde tek seçenekleri olmuştur. I. Konstantin'in Byzantion'u imarı ve ticaret yoluyla verimli Karadeniz'in kuzeyinden tarım ürünlerinin yeni başkent Konstantinopolis'e ulaşması bu yolun önem kazanmasının başlica nedenlerindendir.

35 Köprü Koordinat: Doğu: 35552153, Kuzey: 4618500. Köprünün ayak açıklığı yaklaşık 4 m olup, genişliği 3 m'dir.

36 Demirköy ve çevresinin maden yatakları açısından önemli bir alan olması bu yolu gerekli kılmaktadır. Demirköy demir kaynakları için bakınız Zülküf Yılmaz-Ali Osman Uysal, "Demirköy Fatih Demir Dökümhanesi 2003 Yılı Araştırma ve Kazı Çalışmaları”, Türk Arkeolojï ve Etnografya Dergisi, Sayı: 6, 2006, ss. 53-66; H. H. Günhan Danışman-Fokke Gerritsen vd., "Demirköy-Samakocuk Iron Foundry: An Industrial Archaeology Project at an Ottoman Metal Workshop Complex in Thrace", Türkiye Bilimler Akademisi Arkeoloji Dergisi (TÜBA-AR), Sayı: 10, 2007, ss. 91-110.

37 Boztaş ile İncesırt köyleri arasında, Rezve (Mutlu) Deresi üzerinde bulunan ve Geç Osmanlı İmparatorluğu Dönemi’ne tarihlenen köprü, kesme taş ile üç kemerli yapılmış, 5 m eninde, 7-10 m kemer açıklığına sahiptir. Bkz. Kirklareli Kültür Varlklan Envanteri II, Ankara 2014, s. 19. 


\section{KAYNAKLAR}

Altuhan, Sema, "XVIII. yy'da Silistre Eyaletinde Haberleşme Ağı: Rumeli Sağ Kol Menzilleri", Osmanl Tarihi Araştırma ve Uygulama Merkezi Dergisi, Cilt 18, Sayı 18, 2005, ss. 1-20.

Archibald, Zosia H., The Odrysian Kingdom of Thrace, Orpheus Unmasked, Oxford Üniversitesi Yayınevi, Oxford 2008.

Arslan, Melih, "Kırklareli Müzesi’ndeki Asilbeyli Lysimachia Definesi”, Belleten, Cilt: 72, Sayı: 263, Nisan 2008, ss. 5-52.

Ashley, James R., The Macedonian Empire, The Era of Warfare Under Philip II and Alexander the Great, 359-323 B.C., McFarland Yayınevi, Londra 1998.

Avramea, Anna, “MÖ. 2. Yüzyıl İle MS. 6. Yüzyıl Arasında Via Egnatia’nın Güzergâhı ve İşlevi”, Sol Kol, Osmanl Egemenliğinde Via Egnatia (1380-1699), Tarih Vakfi Yurt Yayınları, İstanbul 1999, ss. 3-7.

Danışman, H. H. Günhan- Fokke Gerritsen- Mustafa Kaçar-Hadi Özbal- Rana Özbal- Gülsün Tanyeli-Ünsal Yalçın- Yılmaz Zülküf,"Demirköy-Samakocuk Iron Foundry: An Industrial Archaeology Project at an Ottoman Metal Workshop Complex in Thrace", Türkiye Bilimler Akademisi Arkeoloji Dergisi (TÜBA-AR), Sayı: 10, 2007, ss. 91-110.

Doğru, Halime, XIII.-XIX. Yüzynllar Arasinda Rumelide Să̆ Kolunun Siyasi, Sosyal, Ekonomik Görüntüsü ve Kozluca Kazası, Anadolu Üniversitesi Yayınları, Eskişehir 2000.

Ertaş, Mehmet Yaşar, "Savaşlarla Şekillenen Yollar: Osmanlı Devletinde Yol Sistemi”, Uluslararası Osmanh Öncesi ve Osmanl Tarihi Araştırmalarn 6. Ara Dönem Bildirileri Kitabı, Meta Basım Matbaacılık, İzmir 2011, ss. 625-652.

French, David, H., Roman Roads and Milestones of Asia Minor, Vol.: 3 Fasc. 3. 1, British Institute at Ankara (Electronic Monograph 1), Ankara 2012.

Gyuzelev, Martin, The West Pontic Coast between Emine Cape and Byzantion during the Frst Millennium BC, Lotus Yayınevi, Burgaz 2008.

Herodotos, Herodot Tarihi, Çev. Müntekim Ökmen, Remzi Yayınevi, İstanbul 1973.

İreçek, Konstantin Yosif, Belgrad İstanbul Roma Askeri Yolu, (Çev. Balkanlı, Ali Kemal), Kültür Bakanlığı Yayınları, Ankara 1990. 
Karaca, Ergün, Milattan Önce Birinci Binde Doğu Trakya, Homer Yayınları, İstanbul 2019.

Karaçam, Nazif, Efsaneden Gerçeğe Kirklareli, Kırklareli Belediyesi Yayını, Kırklareli 1995.

Kıraç, Binnur- Burcu B. Cantimur-Mevlüde Kaptı, "Tarihi Kâgir Köprülerde Koruma Yaklaşımlarının İrdelenmesi: Menekşe/Nakkaş (Roma) Köprüsü, Odabaşı Köprüsü ve Ferhatpaşa Köprüsü”, 5. Tarihi Eserlerin Güçlendirilmesi ve Geleceğe Güvenle Devredilmesi Sempozyumu, Erzurum 2015, ss. 435-443.

Kirklareli Kültür Varlklan Envanteri I-II, Ankara 2014.

Kuelzer, Andreas, "The Byzantine Road System in Eastern Thrace", Byzantinische Forschungen, Cilt: 30, 2011, ss. 179-201.

Madzharov, Mitko, Roman Roads in Bulgaria. Contribution to the Development of Roman Road System in the Provinces of Moesia and Thrace, Faber Yayınevi, Veliko Tarnovo 2009.

Marcus Iulianus Iustinus, Epitome of the Philippic History of Pompeius Trogus, Çev. Yardley, J. C., Atlanta 1994.

Pasinli, Alpay-Turan Gökylldırım-Turhan Birgili- Fırat Düzgüner, "İnceğizMaltepe Nekropolü 1992 Yılı Kurtarma Kazısı", IV. Müze Kurtarma Kazılan Semineri, 1994, ss. 339-356.

Pasinli, Alpay- Turan Gökyıldırım- Fırat Düzgüner, "İnceğiz-Maltepe Nekropolü 1993 Yılı Kurtarma Kazısı", V. Müze Kurtarma Kazllan Semineri, 1995, ss. 345364.

Pasinli, Alpay-Turan Gökylldırım- Frrat Düzgüner- Ferahnur Güven, "Çatalca-İnceğiz Köyü Maltepe Nekropolü 1994 Yılı Kurtarma Kazısı”, VI. Müze Kurtarma Kazllan Semineri, 1996, ss. 205-219.

__, "Çatalca-İnceğiz Köyü Maltepe Nekropolü 1995 Yılı Kurtarma Kazıs1", VII. Müze Kurtarma Kazılarn Semineri, 1997, ss. 77-88.

Sayar, Mustafa Hamdi, "Kırklareli'nde Persler: Dareios'un Kırklareli Üzerindeki Seferi”, Yildız Dağlarn ve Yakın Çevresi Tarih Araştrmaları, Arkeoloji ve Sanat Yayınları, İstanbul 2006, ss. 40-43. 
— "Via Egnatia on Eastern Thrace", Via Egnatia Revisited. Common Past, Common Future with the Lectures of the Conference of February 2009, Driebergen 2010, ss. 43-44.

Şahin, Iş1k, "Roma Yolu "Via Egnatia”, Turan, Sibel (ed.), Keşan Sempozyumu Bildiri Tam Metinleri, 15-16 Mayss 2003, İstanbul 2006, ss. 70-74.

Yılmaz, Zülküf- Ali Osman Uysal, "Demirköy Fatih Demir Dökümhanesi 2003 Yılı Araştırma ve Kazı Çalışmaları", Türk Arkeoloji ve Etnografya Dergisi, Sayı: 6, 2006, ss. 53-66. 


\section{EKLER}

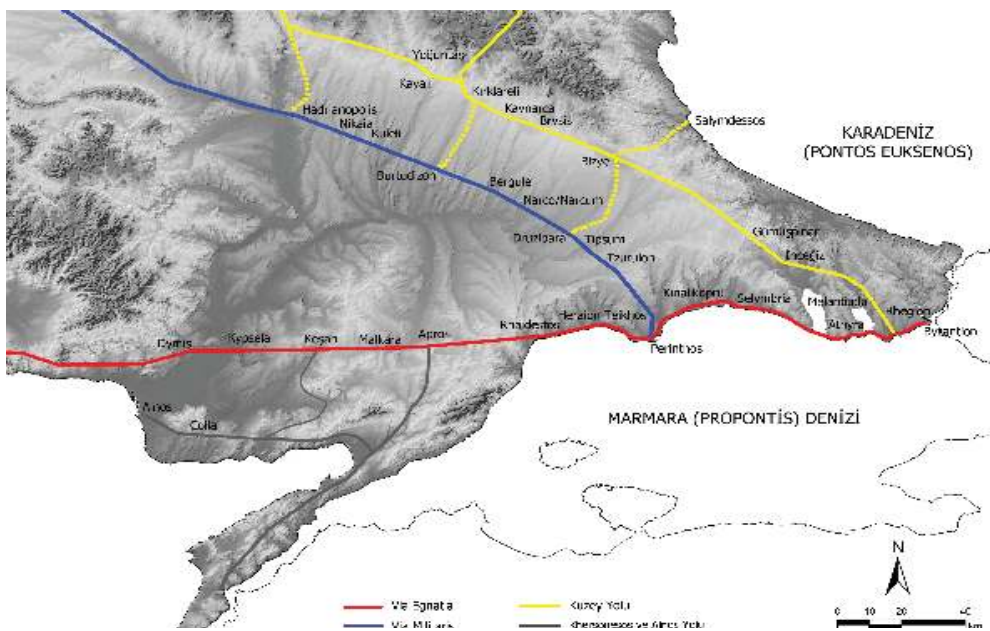

Harita 1: Doğu Trakya Yolları

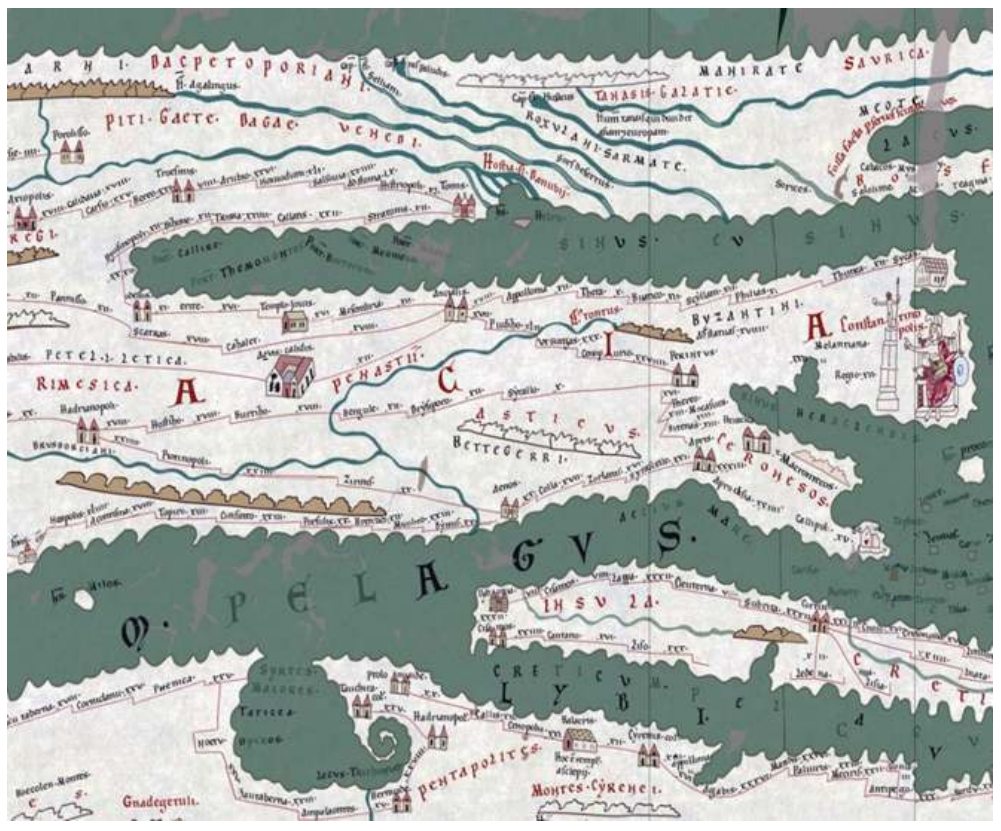

Harita 2: Tabula Peutingeriana'da Doğu Trakya Yolları 


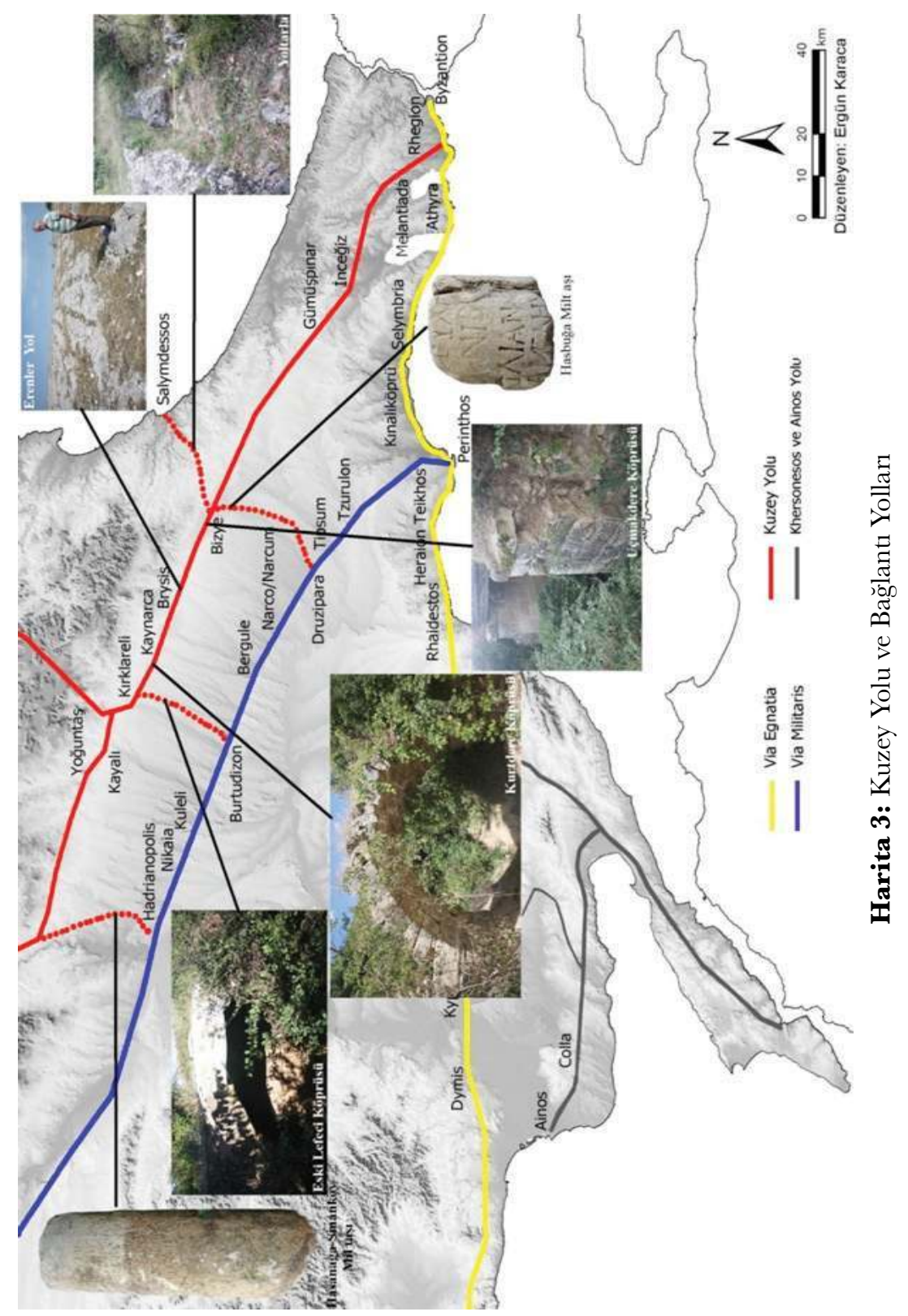




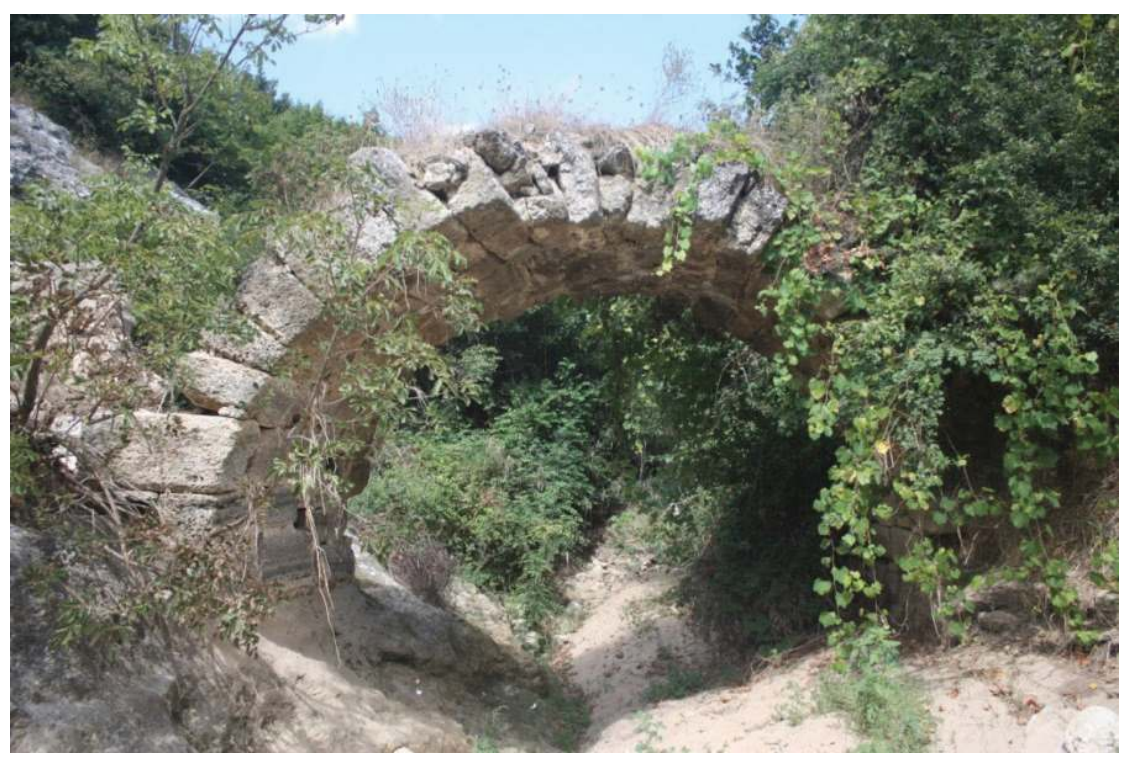

Resim 1: Kurtdere Köprüsü (Güneyden)

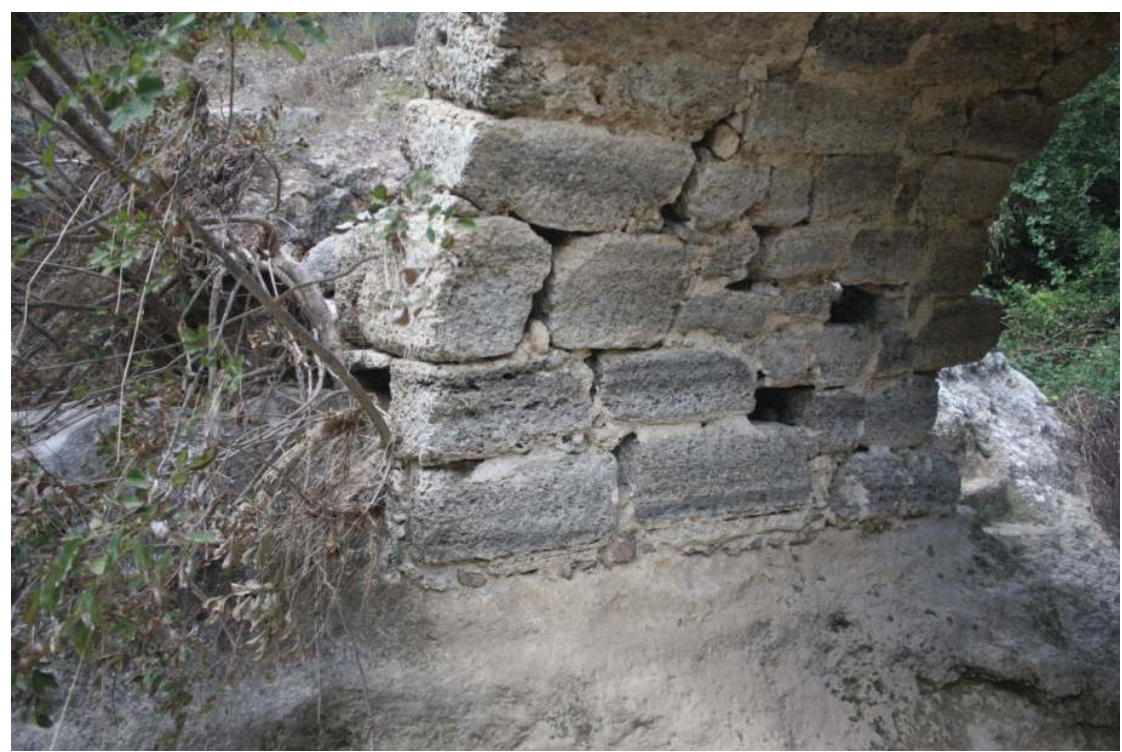

Resim 2: Kurtdere Köprüsü, Batı Ayağı 
Ergün Karaca

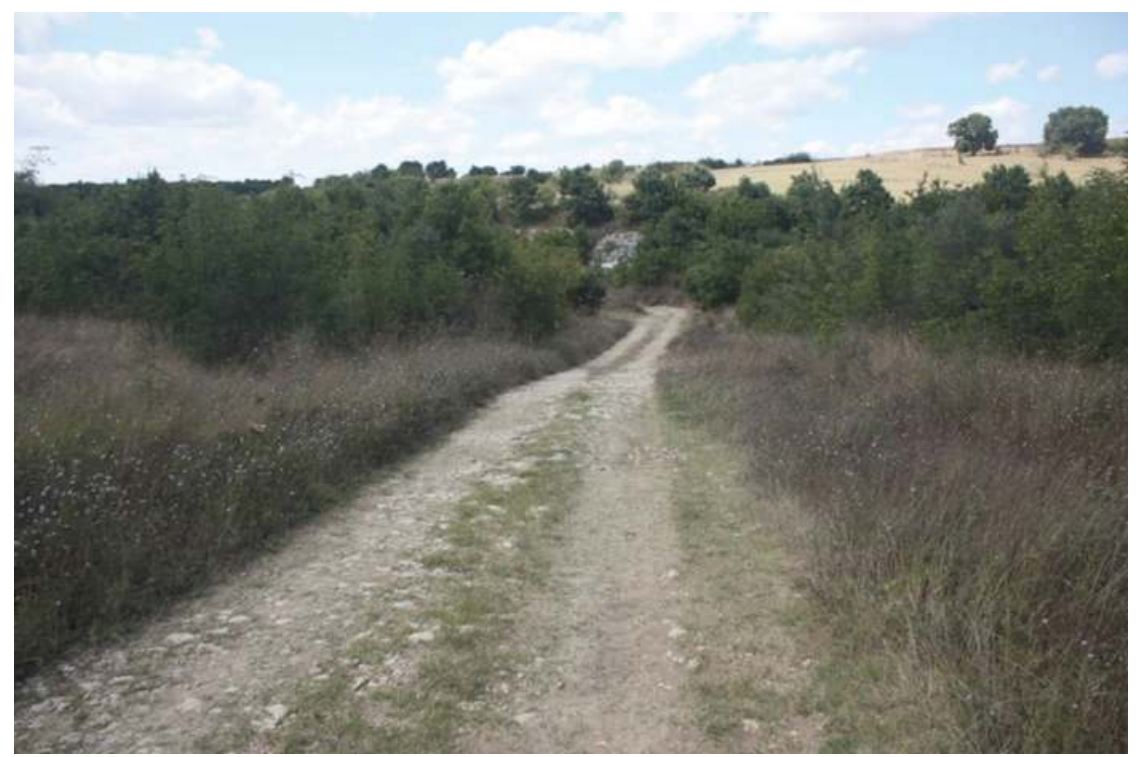

Resim 3: Kurtdere Köprüsü ve Yol Kalıntısı

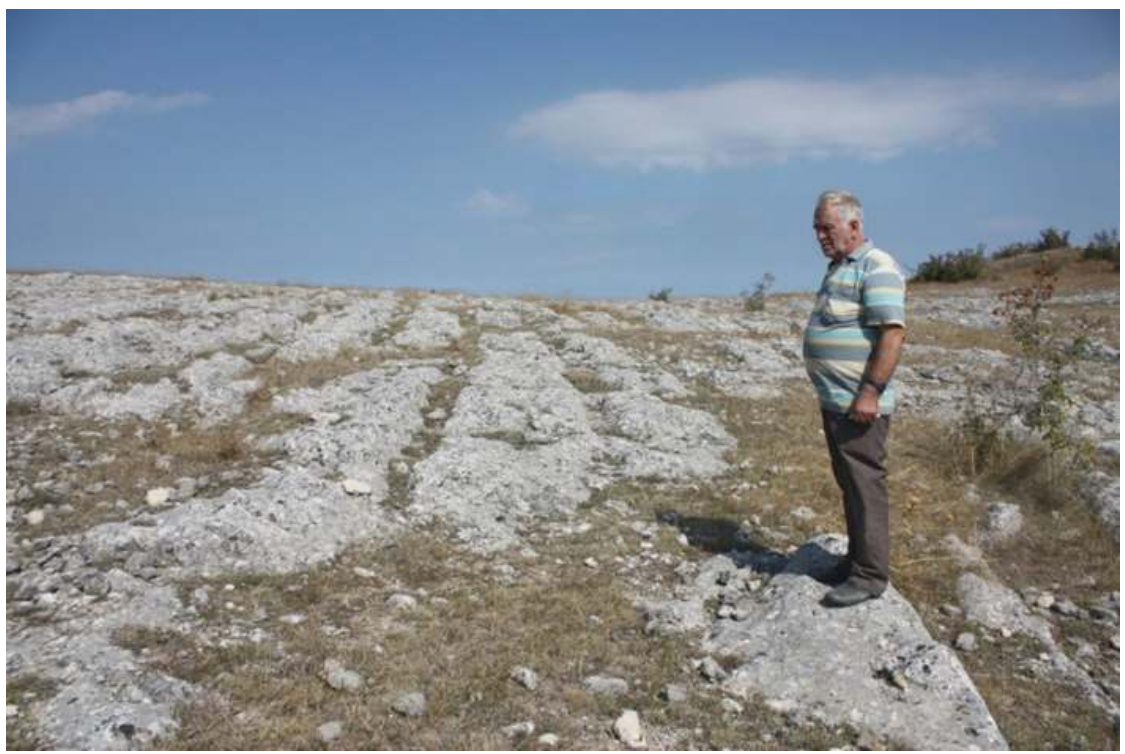

Resim 4: Erenler Köyü Yol İzleri 


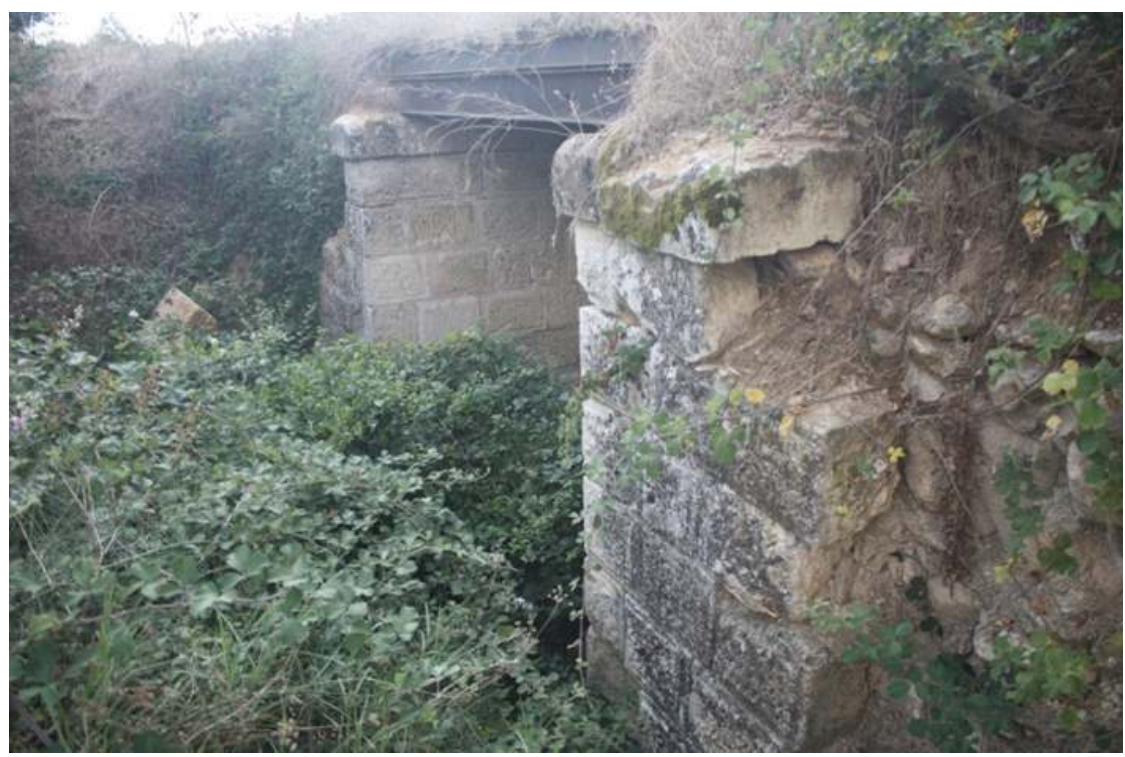

Resim 5: Uçmakdere Köprüsü

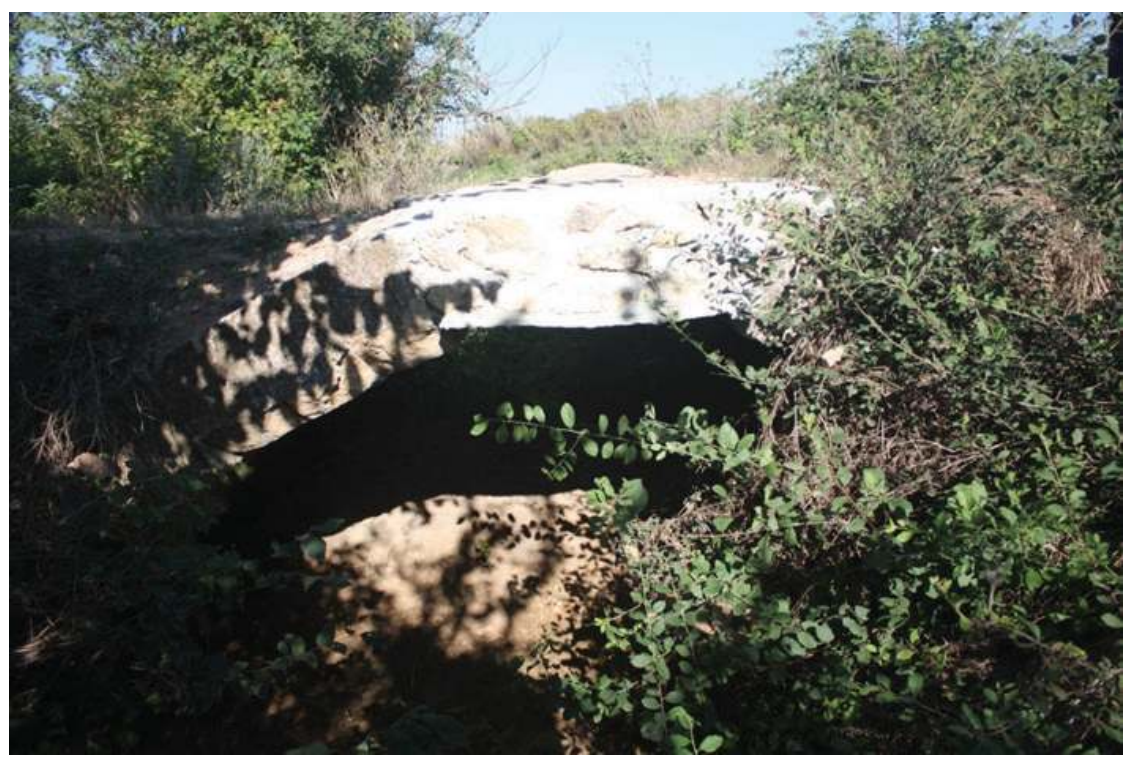

Resim 6: Eski Lefeci Köprüsü 
Ergün Karaca

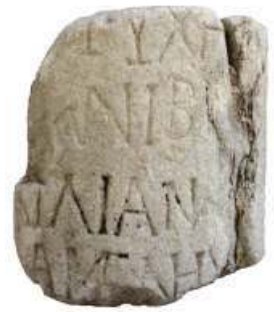

Resim 7: Hasbuğa Mil taşı Parçası

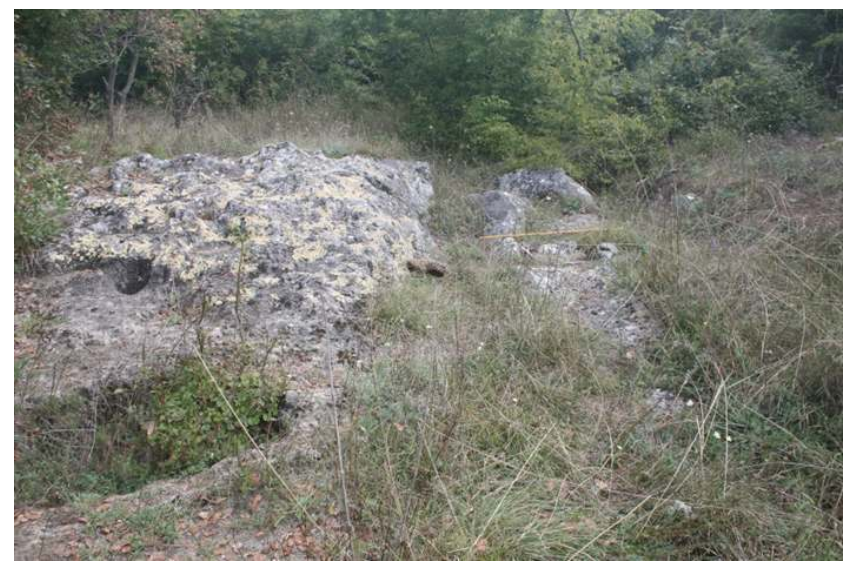

Resim 8: Vize-Akpınar Köyü Yoltarla Yol İzi

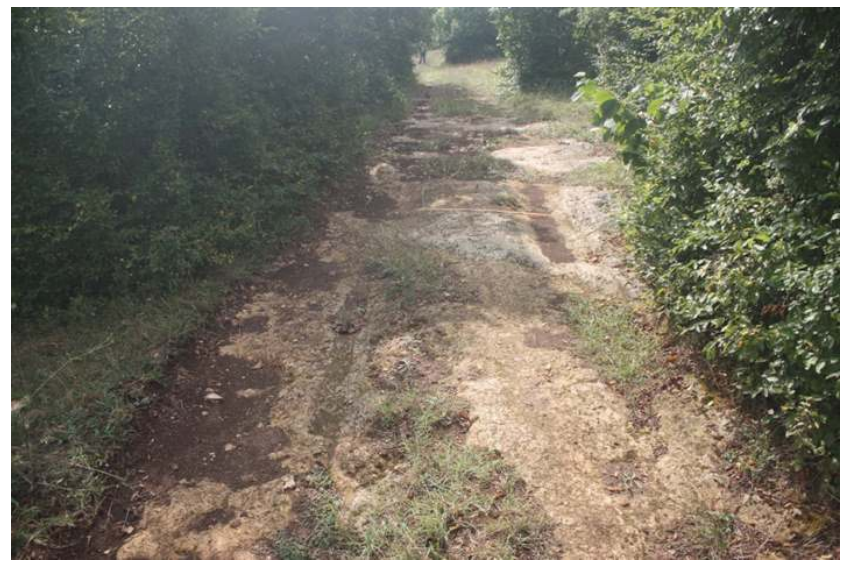

Resim 9: Vize-Akpinar Köyü Küpler Yol İzi 